\title{
EDITORIAL
}

\section{World Call for Action}

Without undue alarmism one can say-and indeed we conceive it a solemn duty to emphasize--that our beautiful world and especially the living creatures of its fragile biosphere are becoming more and more gravely threatened by the inexorable rise of human population pressures. The doom-watchers say there is no hope for the future, but to this we do not subscribe. The ignorant say there is no danger, and this we deny as even far worse. The truth surely lies somewhere between-being that continuing unenlightened, grasping, and highly profligate, use of Earth's limited space and other resources, pose for Man and Nature the greatest threats with which they have ever been confronted. This situation, coupled on one hand with Man's failure to limit his own numbers and, on the other, with some bad luck in matters of weather and climatic change, put the world as we know it in jeopardy. The simple, incontrovertible fact is that we cannot continue exponential growth indefinitely on a finite globe-our only habitable Earth.

We have belaboured most of these points before, particularly in these columns and in The Environmental Future (Macmillan, London, and Barnes \& Noble, New York, 1972), and would not wish to lay ourselves open to the charge of doing so ad nauseam. Rather would we wish to point out, in the most positive way, that Man now has the knowledge and full capacity to save himself and Nature - that this can most assuredly be done. With wise planning and careful execution, Man can even preserve environmental integrity in the face of continued economic advance-particularly towards the attainment of a fuller life among his less-fortunate brethren-hence the theme of our next-projected International Conference on Environmental Future: 'Growth Without Ecodisasters'.

Yet the time left for saving our world is growing alarmingly short, with the rumblings and threats all the time increasing in range, numbers, and volume. Thus since we wrote our 'Thoughts on Some Conceivable Ecodisasters', consisting merely of a selection of thirty of the seemingly most possible, as published in our Autumn issue last year, there have emerged some others. Examples in our No. 1 category of the Atmosphere alone include such climatic possibilities as those described by our Advisory Editor Professor Reid A. Bryson in the following pages of this very issue, and such pollutional ones as possible further threats to the all-important ozone shield in the stratosphere (as mentioned in the first Editorial in our latest issue).

So clearly real action on behalf of the world environment is imperative, and this must be mainly through the governments of the nations of the world - guided by the United Nations and their specialized agencies, in particular the United Nations Environment Programme (UNEP). This young body needs to be given, and to use, real 'teeth'-such as at present appear to be widely lacking for reasons that are largely outside UNEP's control. Yet anyone who may question the depth of their concern or the drive of their intentions should read the paper of their Executive Director, Maurice F. Strong, entitled 'Progress or Catastrophe: Whither Our World?' published in our latest issue. There are also numerous non-governmental organizations, which by-and-large do good work, though their rivalry for the painfully limited funds of the present financial era is not helping to improve overall efficiency.

It is basically the governments of the world that can save it for the future. If they continue in the widely selfish and/or short-sighted manner displayed for example at the recent United Nations Conferences on Population, Food, and the Law of the Sea, human civilization as we know it, and even the biosphere, may well be doomed. But if proper use is made of Man's unique capabilities and the knowledge already accumulated, or now emanating from research all over the world, there seems every likelihood that the biosphere will be saved. We are quite confident that it can be.

But action is urgently needed, and to this end we adjure our readers to consider carefully the petition to the United Nations that is printed on the reverse of this page and, if they agree to its provisions, write in forthwith or cable to EARTHCARE in the manner suggested at the foot of that page 162.

N. P.

Environmental Conservation, Vol, 2, No, 3, Autumn 1975--(C) 1975 The Foundation for Environmental Conservation-Printed in Switzerland. 